\title{
Empreendedorismo intensivo em conhecimento: elementos para uma agenda de pesquisas sobre a ação empreendedora no Brasil
}

\section{Resumo}

O estudo parte da necessidade de propor uma alternativa ao debate atual sobre o empreendedorismo intensivo em conhecimento, que tem privilegiado, em especial no Brasil, os estímulos políticos-institucionais como condicionantes do fenômeno, em detrimento da ação empreendedora propriamente dita. O artigo busca articular alguns avanços conceituais da teoria geral da ação empreendedora com aspectos empíricos observados a partir do comportamento econômico de empreendedores, em especial daqueles que manifestam uma orientação mais aberta ao uso comercial do conhecimento científico e tecnológico. O argumento sustenta a importância de complementar uma perspectiva corrente de que esses empreendedores decidem agir apenas quando são compelidos por condições objetivas dadas pelo contexto. Para tanto, propõe-se uma agenda de pesquisa para compreender como o fenômeno vem ocorrendo no Brasil, que atribua maior importância ao estudo do processo específico da ação empreendedora destes empreendedores do conhecimento, sua conduta estratégica e a forma como conectam trajetórias e mobilizam redes profissionais para perceber oportunidades e fazer escolhas ${ }^{1}$.

Palavras-chave: Empreendedorismo intensivo em conhecimento. Ação empreendedora. Inovação. Sociologia do empreendedorismo.

\footnotetext{
${ }^{1}$ Este artigo é desdobramento e apresenta resultados parciais do projeto "Tomada de Decisão e Ação Empreendedora: Estudo sobre o empreendedorismo em pequenas e médias empresas de base tecnológica, no Brasil", pesquisa financiada por meio de recursos de Edital Chamada Universal - MCTI/CNPq no 14/2014.
} 


\title{
Knowledge-intensive entrepreneurship: outline of a research agenda on entrepreneurial action in Brazil
}

\begin{abstract}
This study emerges from the need to propose an alternative to the current debate on knowledge-intensive entrepreneurship, which has focused, especially in Brazil, on the political-institutional incentives as the drives of the phenomenon, to the detriment of the entrepreneurial action itself. The paper attempts to articulate some conceptual advances of the general theory of entrepreneurial action with empirical aspects observed in the economic behavior of entrepreneurs, especially those that show a more open orientation towards the commercial use of scientific and technological knowledge. The argument emphasizes the importance of complementing a current perspective that these entrepreneurs choose to act only when they are compelled by the objective conditions given by the context. Therefore, a research agenda is proposed seeking to understand how the phenomenon has been taking place in Brazil, which attaches greater importance to the study of the specific process of entrepreneurial action by these knowledge entrepreneurs, their strategic behavior and the way they connect trajectories and mobilize professional networks to perceive opportunities and make choices.
\end{abstract}

Keywords: Knowledge-intensive entrepreneurship. Entrepreneurial action. Innovation. Sociology of entrepreneurship. 


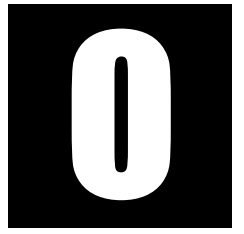

Brasil destaca-se em pesquisas reconhecidas internacionalmente (GEM, 2014) como um dos países com maior contingente de empreendedores no mundo. Em 2014, a taxa de empreendedorismo foi de $34,5 \%$, superando países como Estados Unidos (20,8), China $(17,1)$, Alemanha $(10,5)$, Índia $(10,3)$ e Itália $(8,7)$. Isso significa que, em cada 100 brasileiros com idade entre 18 e 64 anos, pelo menos 34 estão, de determinado modo, envolvidos com alguma atividade empresarial - índice significativamente maior que os $21 \%$ registrados em 2002. Destaca-se, ainda, que a taxa de empreendedores iniciantes $(17,2 \%)$ - aqueles que estão empreendendo há menos de 42 meses - representa praticamente a metade do total de empresários. Porém, deve-se registrar que ainda predomina estruturalmente no país o empreendedorismo informal (78\%), em mercados muito explorados e com baixo potencial de geração de emprego e renda, reafirmando um diagnóstico de quase dez anos, de que "a imagem da situação atual dos empreendimentos brasileiros demonstra que a economia nacional se encontra ainda em estágio inicial de desenvolvimento no que concerne à sua capacidade de gerar empreendimentos inovadores" (Silvestre et al., 2008, p. 14).

O fato novo nesse contexto é a recente disseminação no Brasil de pequenas e médias empresas de base tecnológica, start-ups e spin-offs, o que tem permitido maior visibilidade à ocorrência de uma forma especial de empreendedorismo, mais sofisticada e de maior valor agregado, ancorada em domínios técnicos de vanguarda e novas tendências de mercado. Essas empresas caracterizam-se por terem na combinação de conhecimentos e tecnologias um insumo fundamental para seu negócio, o que já seria condição suficiente para concebê-las como uma novidade promissora frente às tendências históricas na trajetória do movimento empreendedor no país. 
Mesmo considerando que tais empresas não despontem em proporção significativa no conjunto das iniciativas empresariais (cerca de $1 \%$, segundo estimado a partir de dados da Anprotec e GEM), sua criação vem sendo bastante estimulada em escolas de negócios, engenharia, computação, saúde, biotecnologia, física, química, engenharia. Também são crescentes os canais de financiamento para atender esse segmento profissional, bem como a formação de associações empresariais exclusivas.

Esse novo tipo de empreendedorismo em crescimento no país, intensivo em conhecimento ${ }^{1}$, tem atraído a atenção de profissionais, investidores, gestores públicos e pesquisadores de diferentes áreas, em razão, sobretudo, de contrastar com as formas predominantes de empreendedorismo existentes no país. Nesse sentido, pelo menos três linhas interpretativas já permitem traçar um panorama parcial acerca desse fenômeno no Brasil, indicando pistas sobre suas causas, origens e implicações econômicas e sociais.

A linha interpretativa mais difundida enfatiza a presença de fatores ambientais como promotores do fenômeno, destacando a importância de mudanças institucionais e de novas políticas governamentais para estimular a transferência de conhecimento produzido em instituições de pesquisa para o setor produtivo (Shinn; Lamy, 2006; Araújo et al., 2005; Dagnino; Dias, 2008; Aranha, 2008; Lemos, 2009). Tais estudos sustentam que o empreendedorismo intensivo em conhecimento encontrou as melhores condições de se desenvolver, a partir de ações institucionais promovidas por meio de medidas que visaram ampliar o estímulo à re-

\footnotetext{
${ }^{1}$ Esse tipo de empreendedorismo foi objeto de estudo nos Estados Unidos, retratado a partir de realidades como a do Vale do Silício, na Califórnia, e a da Rota128, entre Boston e Cambridge (ver Saxenian, 1994; Carnoy et al., 1997; Neff et al., 2005; Whittaker, 2009; Ferrary; Granovetter, 2009). Também é referido como empreendedorismo inovador (Silvestre et al., 2008), empreendedorismo de base tecnológica (Araújo et al., 2007; Cozzi et al., 2008), empreendedorismo high tech (Guimarães; Azambuja, 2010); na literatura internacional, Knowledge-intensive entrepreneurship (KIE).
} 
lação universidade-empresa (Arbix, 2010; Arbix; Consoni, 2011), que teriam favorecido seu cultivo e formação em incubadoras tecnológicas e sua instalação, na fase madura, em parques científico-tecnológicos e condomínios de inovação.

A explicação é a de que o empreendedorismo tecnológico encontraria maior eco em meio aos referidos habitats de inovação, que vêm sendo criados junto a Universidades, Centros de Pesquisa e parques industriais. Seguindo a tese de que a inovação emana de um processo sustentável e durável de inter-relações entre a ciência e o mercado, mediadas por políticas governamentais de Ciência, Tecnologia e Inovação (Stokes, 2005; Etzkowitz, 2009), o argumento principal dessa perspectiva sustenta que a maior permeabilidade entre as fronteiras que originalmente separaram essas organizações contribuiria para a ocorrência do empreendedorismo ancorado em pesquisa e avanços tecnológicos. No Brasil, tal argumento encontra subsídios em correlações positivas entre o surgimento de start-ups e spin-offs e a formação de incubadoras e parques, em localidades beneficiadas por políticas de inovação.

Uma segunda linha interpretativa tem acompanhado mais de perto as mudanças que ocorrem na cultura e nas práticas científicas em universidades brasileiras. Estudos sobre novas tendências da produção do conhecimento mostram que um contingente crescente de pesquisadores passou a reconhecer a importância de sua contribuição para a inovação tecnológica, mesmo que, na maior parte das vezes, ainda atuem de forma isolada (Sobral, 2011). Nesse sentido, o empreendedorismo tecnológico é apresentado como uma evidente manifestação de novas orientações científicas e como representação de um novo estágio da mentalidade acadêmica, que se amplia em direção a uma atitude também empreendedora, embora não sem sofrer resistências institucionais de uma cultura ainda muito arraigada na pesquisa básica e na produção acadêmica 
(Barcelos; Mocelin, 2016). Embasados na tese de que o desenvolvimento econômico afeta a organização da pesquisa e as práticas científicas mais tradicionais do campo acadêmico (Owen-Smith; Powell, 2001; Colyvas; Powell, 2006, 2007), tais estudos revelam as dificuldades e as limitações que ainda cerceiam a difusão mais ampla do empreendedorismo tecnológico a partir das Universidades. No entanto, constatam que as persistentes barreiras de ordem institucional não são intransponíveis, uma vez que demonstram existir cada vez maior contingente de cientistas empenhados em assumir esse desafio, com disposição para promover marcos mais ousados de carreira científica.

A terceira linha interpretativa tem se dedicado a mapear casos de empreendedorismo tecnológico, observadas as características das empresas e dos empreendedores em suas atividades de inovação. Estudos com foco em empreendimentos inovadores os têm caracterizado como empresas iniciantes, de pequeno e médio porte, que despendem recursos para realizar pesquisa e desenvolvimento, propondo soluções criativas para demandas sociais, e que, de alguma maneira, podem repercutir como mercados promissores (Rossiter, 2003; Silvestre et al., 2008; Cozzi et al., 2008; Lemos, 2009; Côrtes et al., 2005). O desempenho dessas empresas é exposto como função das redes de colaboração dos empreendedores e da forma como eles adotam práticas de gestão da inovação com base em conhecimento científico e tecnológico de ponta. É nesse sentido que outros autores direcionam estudos para o agente empreendedor, destacando seu perfil, trajetória, habilidades e qualidade de suas redes de relações (Guimarães; Azambuja, 2010; Guimarães, 2011).

Esses estudos descrevem o fenômeno em questão como sendo desencadeado a partir da iniciativa de agentes altamente qualificados, pesquisadores e tecnólogos, profissionais high tech, cientistas de carreira e/ou jovens pesquisadores recém-graduados, muitos mestres e doutores 
em atividades científicas, de comunicação, biotecnológicas, artísticas e criativas. Os casos mapeados nestes estudos mostram que esse tipo de empreendedorismo é movido por agentes que identificam, avaliam e exploram oportunidades, mobilizando habilidades cognitivas diferenciadas (Guimarães; Azambuja, 2010). Por serem empreendedores dotados de capital científico, colaboram intelectualmente para rearranjar recursos disponíveis (Guimarães, 2011) e se articulam em redes profissionais densas, inclusive internacionais (Rossiter, 2003; Guimarães, 2012). Para esses autores, as experiências observadas no Brasil reproduzem tendência internacional, o crescimento de um segmento profissional dispostos a criar empresas de tecnologia, enfrentando riscos e a aceitando maior flexibilidade na carreira (Saxenian, 1994, 2008; Eliasson, 2006; Ruzzier et al., 2006; Tremblay, 2009).

Esse panorama geral permite considerar que o processo empreendedor que tem essa natureza tecnológica se constitui essencialmente distinto das formas mais tradicionais de empreendedorismo. Conforme Lemos (2009), o fenômeno empreendedor em questão diferencia-se de outras formas de empreendedorismo uma vez que a concepção, o planejamento e a gestão dos empreendimentos originados de ciência e tecnologia têm natureza, características e motivações diferentes daqueles sem dependência do conhecimento científico-tecnológico. Assim, do mesmo modo que se deve considerar que diferentes formas de empreendedorismo ilustrem diferentes perfis de empreendedores (Thornton et al., 2011), é plausível sugerir que a natureza dos empreendimentos tecnológicos envolva também uma maturação mais complexa do próprio processo de ação empreendedora. É neste sentido que sugerimos caminhos para complementar algumas lacunas existentes nos estudos sobre o tema.

Incursões empíricas que temos realizado em estudo exploratório, realizado a partir de entrevistas e aplicação de questionários com sócios de 
startups e spin-offs criadas no Brasil nos últimos cinco anos, permitem observar ainda que o empreendedorismo tecnológico passa a ocorrer no país também de forma mais espontânea e autônoma, trasbordando sua ocorrência normal em habitats de inovação, como incubadoras e parques científico-tecnológicos. Esse é o caso, por exemplo, de novas pequenas empresas nas áreas de serviços de tecnologia da informação, webdesign, aplicativos e jogos eletrônicos, em que há inovação em serviços e em processos, mas menos dependentes de infraestrutura universitária e recursos públicos, como no caso de segmentos de saúde, biotecnologia e nanotecnologia. Essa evidência preliminar sugere haver iniciativas desse tipo empreendedor menos dependentes da tutela de instituições de pesquisa consolidadas, indicando uma possível maior consolidação do fenômeno no país.

É partindo dessas observações que se propõe, neste ensaio, complementar o debate atual sobre o tema no Brasil, que ainda tem privilegiado os estímulos políticos-institucionais como condicionantes mais determinantes do fenômeno, em detrimento da ação empreendedora propriamente dita. Entre tantos aspectos que permeiam o estudo do empreendedorismo em geral, têm-se destacado no debate internacional atual as condições subjetivas que permeiam as etapas do processo da ação empreendedora. No presente artigo, propõe-se ajustar este debate à compreensão da realidade do empreendedorismo intensivo em conhecimento, no Brasil, adequando-o, com a inclusão da dimensão inovadora/tecnológica. Atribuindo maior importância aos aspectos subjetivos que integram o processo da ação empreendedora, o argumento analítico aqui defendido procura complementar uma visão difundida no país de que os empreendedores high tech decidem agir, porque são compelidos por condições objetivas.

Com a intenção de levantar elementos para uma agenda de pesquisa de cunho mais subjetivo, baseado na interpretação do contexto pelos 
agentes econômicos e em sua decisão de empreender, e considerando a importância estratégica da maturação, no Brasil, do fenômeno empreendedorismo intensivo em conhecimento, o presente estudo assume como pressuposto que essa forma de empreender pode ser reconhecida como um padrão mais desenvolvido de ação empreendedora. Por essa razão, busca-se investigar esse comportamento econômico, considerando-o como um parâmetro que requalifica a própria concepção conceitual de empreendedorismo em linhas gerais.

Além desta introdução, o artigo está dividido em outras cinco partes. Nas duas primeiras, revisamos como a teoria geral do empreendedorismo tem avançado para uma interpretação mais próxima dos processos cognitivos mobilizados no agir empreendedor, destacando a literatura mais recente das áreas de gestão e administração, que concentra a análise do empreendedorismo sobre os processos mentais ativados pelos agentes, com ênfase em noções como decisão, escolhas, e capacidade cognitiva. Na terceira parte, apresentamos alguns dados sobre o perfil médio do empresário brasileiro, apontando para limitações inerentes ao desenvolvimento atual do movimento empreendedor no Brasil. Na quarta parte, articulamos conceitos da teoria da ação empreendedora com aspectos empíricos observados em pesquisa sobre o comportamento econômico de socioempreendedores de 68 pequenas e médias empresas de base tecnológica que manifestam orientação mais aberta ao uso comercial do conhecimento científico e tecnológico. Na parte final do artigo, sugerimos proposições que podem subsidiar teoricamente uma agenda alternativa de pesquisa sobre o tema em questão, estabelecendo um diálogo sobre como a teoria da ação empreendedora pode contribuir com o conhecimento acumulado nas Ciências Sociais acerca da racionalidade dos agentes econômicos. 


\section{Redirecionamentos na teoria geral do empreendedorismo}

Desde meados do século 19, o empreendedorismo passou a ser considerado como um dos comportamentos sociais mais importantes e difundidos na história econômica mundial. Não por acaso, seu estudo apresenta caráter eminentemente sociológico em vários sentidos (Thornton, 1999; Swedberg, 2000; Granovetter, 2000). Mesmo sendo recorrentemente conceituado como criação de novas empresas (Schumpeter, 1985), formação de novos negócios (Gartner, 1985) e busca por novos mercados (Lumpkin; Dess, 1996), o empreendedorismo foi também analisado como tipo de conduta social (Weber, [1920] 2004), padrão comportamental (Hirschman, 1958), aspiração pessoal (McClelland, 1961), motor do desenvolvimento (Schumpeter, [1934] 1985), fonte de inovação (Penrose, 1959; Nelson; Winter, 1982), modalidade de ação com função na dinâmica dos mercados (Kirzner, 2012), expressão de liderança (Mintzberg, 1983), formação técnico-administrativa (Drucker, 1986) e processo cultural incrustado (Jack; Anderson, 2002; Martinelli, 2009; Thornton et al., 2011).

Mesmo distante de abordar o que já foi produzido sobre a temática, essa breve revisão de perspectivas sobre empreendedorismo permite constatar como esse tipo de comportamento econômico permeia o interesse de distintos campos do conhecimento, desde a economia e a administração até a psicologia e a sociologia. Na vasta literatura, pode-se identificar uma gama de concepções sobre o significado do processo empreendedor que incluem as suas causas e consequências socioculturais, importância econômica, relevância estratégica, função dinâmica nos mercados. Entre as abordagens, algumas tendem a enfatizar a dimensão ambiental em que transcorre a ação empreendedora, dando destaque às condições objetivas em que os empreendedores podem agir, enquanto outras propõem enfatizar a dimensão comportamental dos agentes que 
desencadeiam essa forma de ação, dando destaque às etapas mentais por que passam os empreendedores quando eles decidem agir.

Os estudos sobre o comportamento do agente empreendedor foram muito tradicionais na sociologia e na psicologia, tendo por objeto de análise a mentalidade desse tipo de ator social, suas relações, interações e motivações. No início do Século 20, Max Weber (2004) já os definia como uma mentalidade econômica típica da economia emergente, que age desafiando valores arraigados e lutando para impor uma nova visão a um mundo de tradições. Em 1934, Joseph Schumpeter (1985) descreveu o empreendedorismo como função econômica dinamizadora do capitalismo, destacando que a ação dos empresários inovadores não se reduzia a uma simples aventura, mas envolvia uma decisão planejada de luta:

No peito de quem deseja fazer algo novo, as forças do hábito se levantam e testemunham contra o projeto em embrião. É, portanto, necessário uma força de vontade nova e de outra espécie para arrancar, dentre o trabalho e a lida com as ocupações diárias, oportunidade e tempo para conceber e elaborar a combinação nova e resolver olhá-la como uma possibilidade real e não meramente como um sonho (Schumpeter, [1934] 1985, p. 93).

Entre as décadas de 1960 e 1980, os chamados neoschumpeterianos adotaram analogias biológicas para reafirmar o processo de mudança tecnológica como motor do desenvolvimento econômico. Penrose (1959) entendia que o desempenho das firmas resultava do "espírito empreendedor" nelas existente. Nelson e Winter (1982) e Dosi (1982) buscaram incorporar a questão tecnológica à teoria da firma, promovendo as noções de aprendizado e de trajetórias tecnológicas. Essa escola procurou aperfeiçoar a concepção de que a firma é o locus de atuação do empresário inovador, chamando atenção para a dinâmica econômica que pode ser proporcionada pelo desenvolvimento das inovações. 
No mesmo período, Hirschman (1958) destacou a habilidosa capacidade dos empreendedores em mobilizar pessoas, induzindo a cooperação de inventores, capitalistas, fornecedores, além de garantir apoio de agências e de manter relações bem-sucedidas com trabalhadores e clientes. McClelland (1961) analisou o comportamento empreendedor como um tipo específico de personalidade que busca realização pessoal, mobilizando-se para a excelência, a obtenção de resultados e o forte desejo de sucesso e reconhecimento. Os referidos autores trataram o empreendedorismo identificando a base da ação empreendedora em aspectos da qualidade da personalidade do agente empreendedor.

Diferente é a abordagem de autores que analisam o empreendedorismo destacando as qualidades técnicas do agente empreendedor. Embora também enfatizem a dimensão comportamental, estudos típicos das escolas de administração e de negócios preferem concebê-la como uma competência técnica, e não como um traço de personalidade. Drucker (1986) definiu que a habilidade fundamental do empreendedor é a sua capacidade de identificar oportunidades que estão esperando ser percebidas. Em sua visão, os indivíduos podem ser treinados para se tornarem administradores competentes, aqueles que assumem práticas decisórias: liderar, manipular distúrbios, alocar recursos, negociar, ter tino para os negócios. Segundo o autor, o empreendedorismo é um fenômeno objetivo, que expressa uma "cultura de negócios", e, nesse sentido, poderia ser ensinado, difundido e cultivado. Para isso serviriam os manuais com práticas programáticas e métodos prescritos, elaborados e aperfeiçoados a partir da experiência empreendedora acumulada.

Nesta mesma linha de raciocínio, Mintzberg (1983) avaliou que o agente empreendedor apresenta comportamento agressivo e busca contaminar outros com seu senso de missão. Ele visualiza possibilidades de mudanças, responde a essas e as explora como uma grande oportunida- 
de. A premissa fundamental é a de que os empreendedores são bons distribuidores e coordenadores de recursos, organizadores desembaraçados, que desenvolvem visões diferenciadas sobre o uso e a combinação de recursos disponíveis.

Seguindo outra linha de entendimento, parte da literatura também defende que a ação empreendedora tende a ser compelida por ambientes propícios à prática empreendedora. Aldrich (1990), com base na ecologia populacional, impulsionou a pesquisa sobre os aspectos pertinentes ao contexto do empreendedorismo, sugerindo que estudar traços individuais de empresários não fornece informações sobre o ambiente em que eles interpretam e dão sentido às suas ações. Considerando essa abordagem da questão, contextos marcados por crescimento econômico evidenciariam maior tendência ao empreendedorismo por oportunidade, enquanto que conjunturas de crise dariam maior margem ao empreendedorismo por necessidade.

Thornton (1999) propôs sintetizar o debate, apontando para a existência de duas perspectivas consolidadas sobre o empreendedorismo, uma escola focada no lado da oferta, que analisa os traços individuais dos empresários, e outra que redireciona a questão para o lado da procura, analisando as influências do contexto. A escola da oferta examina os mecanismos potenciais para a agência, enquanto o lado da demanda enfatiza a atração que o contexto exerce sobre a iniciativa empreendedora. No entanto, a autora argumenta que essa pode ser uma classificação equivocada, uma vez que a fundação de uma empresa pode depender do empreendedor individual, mas também é claro que ele não pode se mobilizar sem que haja um contexto atrativo, que lhe permita tomar a decisão de empreender.

Assim, sem desconsiderar as condições históricas e conjunturais em que ocorre a ação empreendedora, recentes perspectivas sugerem que o 
estudo do empreendedorismo engendre, como elemento central de investigação, a reconstrução do processo da ação empreendedora. Trata-se de compreender o sentido que orienta a ação do agente empreendedor até a concretização do empreendimento, e a forma como essa ação envolve a exploração de oportunidades inexploradas de ganho econômico (lucro) e/ou simbólico (realização). Nesses termos, o empreendedorismo passa a ser investigado como um intenso processo cognitivo, que abrange etapas interconectadas de identificação, avaliação e exploração de oportunidades, para a criação de bens ou serviços futuros (Shane; Venkataraman, 2000; Gaglio; Katz, 2001; Choi; Shepherd, 2004; Alvarez; Barney, 2007). Nessa direção, reconhece-se que a ação empreendedora envolve práticas decisórias de maior profundidade subjetiva, algumas intimamente vinculadas à iniciativa de indivíduos que agem sobre uma oportunidade que eles julgam valer a pena perseguir (McMullen; Shepherd, 2006; Haynie et al., 2009).

Desse modo, podemos definir a ação empreendedora como a vontade concretizada de indivíduos que buscaram criar algo com potencial valorização social e em que previamente já depositavam expectativa de obter ganhos. Essa vontade depende da disposição dos agentes para desencadeá-la em uma linha regular de ação, que exige dispêndio de tempo e de recursos. Trata-se de um exercício reflexivo, no qual os agentes pressupõem possíveis consequências de suas ações, embora não as possam controlar inteiramente no curso da ação. Ao tomar decisões, o agente empreendedor passa a agir sobre suas escolhas - o caminho que julgou mais adequado seguir - e a monitorar determinada linha de ação que desencadeou.

Nesse sentido, parece pertinente destacar o esforço da escola austríaca de economia em diferenciar a ação do empreendedor nos mercados como distinta de qualquer ação no campo econômico ou mesmo a do 
homem de negócios. Enquanto a atividade empresarial pode ser compreendida como a ação resultante de escolhas subjetivamente calculadas a partir de condições e oportunidades de lucro já conhecidas; o empreendedorismo, por contraste, também é definido por uma ação que envolve escolhas, porém a partir de um estado mental especial de atenção para identificação de oportunidades de ganho ainda não exploradas (GianturCo, 2014; lorio, 2011). Este estado mental, que diferencia o empreendedor como uma forma específica de ação econômica, é sintetizado genericamente pela expressão "estado de alerta", cunhada pelo economista Israel Kirzner (2012).

Pode-se afirmar, então, que o empreendedor não age (empreende) fora de contextos, porém, igualmente ou mais decisivo, pode-se considerar que ele não age sem a formulação subjetiva da disponibilidade de recursos e custos envolvidos no curso de ação que entende ser necessário para alcançar a oportunidade inexplorada de lucro por ele detectada. Sua ação se desenrola em meio à incerteza genuína e disposição subjetiva, pois a relação entre meios (custos) e fins (ganhos) para realizar a oportunidade ainda existe sob a forma de um conhecimento descoberto como resultado de um processo mental imaginativo, não como uma mera reação a estímulos objetivos em que as relações entre meios e fins já são previamente conhecidas e, por isso, precificadas (Gianturco, 2014; lorio, 2011; Kirzner, 2012).

No caso específico do empreendedorismo tecnológico, é bastante recorrente a abordagem de que o fenômeno vem sendo condicionado por um contexto de novas políticas de inovação e de mudanças nas instituições científicas, favorável à sua expansão. No entanto, cabe igualmente avaliar se essa forma de empreendedorismo constituir-se-ia como uma modalidade por "oportunidade-demandada", como se faz crer, ou seria mais complexa. Nesse sentido, é necessário adentrar mais profundamen- 
te o fenômeno. Embora não se possa negar a importância de associar a sua origem como sendo estimulada pelas novas condições de atuação com que se deparam pesquisadores e tecnólogos, deve-se reconhecer que essa interpretação da questão privilegia fatores externos à ação empreendedora para explicá-la, dando pouca relevância para os aspectos intrínsecos ao processo empreendedor, em especial aqueles que dizem respeito ao que leva esses indivíduos a decidirem empreender.

\section{Apontamentos sobre o processo da ação empreendedora}

As questões teóricas sobre o empreendedorismo, acima referidas, ajudam a delimitar um conjunto de aspectos conceituais presentes no atual debate sobre a ação empreendedora, o qual se tem centrado sobre as condições em que os empreendedores percebem oportunidades, as avaliam e agem sobre elas. Alguns autores analisam as condições em que um empreendedor pode agir, tomando como objeto: as fontes de oportunidades (Shane, 2000; Holcombe, 2003; Timmons; Spinelli, 2003; Eckhardt; Shane, 2003), se estão esperando serem descobertas ou se podem também ser criadas (Shane; Venkataraman, 2000; Alvarez; Barney, 2007); os laços entre empreendedores, instituições e agentes econômicos que favorecem a descoberta de oportunidades (Ferrary; Granovetter, 2009); e a forma como mecanismos institucionais incentivam a ação empreendedora (Foss; Foss, 2008).

Outros autores têm direcionado sua atenção às condições em que um empreendedor decide agir (Gaglio; Katz, 2001; Choi; Shepherd, 2004; Mcmullen; Shepherd, 2006; Shepherd et al., 2007; Haynie et al., 2009; Autio et al., 2013), aprofundado o debate sobre o "estado de alerta empresarial" e concentrando-se mais detidamente no processo cognitivo que condiciona a ação empreendedora (Gaglio; Katz, 2001; Mcmullen; 
Shepherd, 2006). Para esses autores, a inserção em redes não é suficiente para que o empreendedor decida agir; é necessário acioná-las de maneira estratégica, participando efetivamente delas e se expondo às informações que transitam por elas.

Gaglio (2004) destaca que o aspecto mais fascinante do comportamento empreendedor é sonhar com coisas que não existem ainda, criá-las e ganhar a aceitação do mercado. Porém, esse não é um processo simples. McMullen e Shepherd (2006) explicam que o "estado de alerta", por si só, não resulta no empreendimento, pois ser empreendedor, logicamente, implica que o alerta já tenha sido exercido. Shane e Venkataraman (2000) já haviam apontado para dois fatores importantes relacionados ao chamado "estado de alerta": a posse de informações prévias e as propriedades cognitivas necessárias para avaliá-las. Para os autores, os indivíduos possuem estoques de informação, o que influencia a habilidade deles para reconhecer oportunidades. Seguindo essa linha de argumentação, Autio et al. (2013) afirmam que, para reconhecer uma oportunidade e decidir explorá-la, os indivíduos precisam combinar seus conhecimentos e motivações com informações complementares. Segundo os autores, há pessoas que, por algumas circunstâncias, detêm melhores informações que outras. Entretanto, apenas com a posse da informação, sem a habilidade cognitiva para identificar novas relações entre meios e fins, a exploração de uma oportunidade pode falhar. 
Figura 1. Condicionantes da iniciativa empreendedora

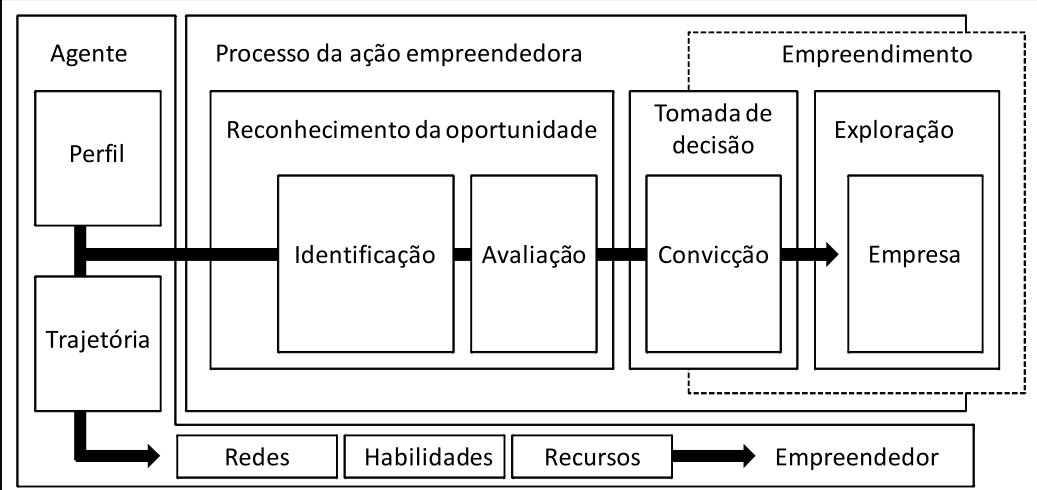

Contexto socioeconômico, institucional e mercados

Fonte: Elaboração dos autores.

Esses aspectos introdutórios são importantes para avançar na interpretação do processo da ação empreendedora. A Figura 1 procura sistematizar alguns desses elementos. Inicialmente, é importante considerar que esse processo de ação tende a ser desempenhado por agentes com determinando perfil e trajetória, que favorecem a iniciativa empreendedora, a qual emerge a partir de capacidades adquiridas e de acesso a redes e recursos variados. Teoricamente, pode-se considerar que a qualidade desses fatores indicaria o nível de sofisticação do empreendedorismo a ser desempenhado pela massa potencial de empreendedores disponíveis em um contexto. Segundo a teoria da ação empreendedora, o reconhecimento de uma oportunidade percorre duas etapas básicas, identificação e avaliação. McMullen e Shepherd (2006) explicam que, na etapa de identificação, os indivíduos são sensibilizados para um determinado conjunto de problemas; ao mesmo tempo, são expostos a outro conjunto de 
informações que lhes permite imaginar possíveis soluções ao problema, momento em que também identificam oportunidades. Segue-se um procedimento de avaliação, durante o qual imaginam um curso de ação, e determinam se este é viável e desejável.

Haynie et al. (2009) argumentam que a avaliação de oportunidades é uma atividade orientada para o futuro, ainda não é a decisão de empreender. No mesmo sentido, Gaglio (2004) definiu que a avaliação de uma oportunidade é a capacidade do agente de criar uma representação imaginária do futuro, antecipando necessidades e criando um plano realista, que possa efetivamente ser colocado em prática. Não é possível combinar recursos inexistentes ou aos quais não se tem acesso. Antes de agir, o agente concebe mentalmente a exploração da oportunidade, através de simulações mentais, imaginando estratégias para entrar em um novo mercado e os diferentes resultados que podem ser alcançados. Essas representações cognitivas incorporam a avaliação de recursos existentes e a possibilidade de acessá-los (Gaglio, 2004).

Entre a avaliação e a exploração de uma oportunidade ainda paira, portanto, uma necessária convicção, uma "tomada de decisão". Hastie (2001) argumenta que a decisão de agir refere-se a como as pessoas combinam desejos (utilidades, valores pessoais, objetivos, fins) e crenças (expectativas, conhecimentos, meios) para escolher um curso de ação. Essa decisão inclui três componentes: (a) cursos de ação (escolha entre alternativas); (b) crenças sobre estados objetivos, processos e eventos (incluindo condições e meios para alcançá-los); e (c) os desejos, valores ou utilidades que descrevem as consequências associadas com os resultados de cada combinação de eventos de ação. "Boas decisões são aquelas que efetivamente mobilizaram os meios que estavam disponíveis em circunstâncias dadas para alcançar os objetivos de quem tomou a decisão" (Hastie, 2001, p. 655-6, tradução nossa). 
Nesse sentido, até a efetiva exploração da oportunidade, devem ser considerados momentos intervenientes de intensa reflexividade, que certamente envolvem grande carga emocional. Segundo Hastie (2001), a decisão de explorar uma oportunidade é a ocasião em que o indivíduo aciona sua imaginação para combinar desejos, conhecimentos, estimativas e crenças, conectando mentalmente o presente, o futuro e o passado, para superar dúvidas (incerteza reduzida), e convencer-se de que algo é possível (risco calculado). Esse momento não é livre de impasses, pois é necessário escolher um caminho a seguir entre as alternativas possíveis. O processo cognitivo acionado é concluído apenas quando os agentes se convencem racional e emocionalmente de que possuem disposição e condições (materiais, relacionais e humanas) para atingir os fins desejados. Shepherd et al. (2007) complementam afirmando que esse processo cognitivo, impulsionado tanto pela formação de representações mentais do indivíduo sobre seu ambiente de atuação quanto pelo seu conhecimento acumulado e sua motivação, é constantemente atualizado por meio de informações que descrevem mudanças no ambiente. Nesse sentido, qualquer decisão pressupõe que o agente empreendedor adquira informação, selecione, analise, estime as consequências, decidindo se vai e como vai agir, isto é, elabora um sentido para sua ação, que reflete a sua vontade.

A ação para criar valor com a venda de produtos e serviços será acionada apenas se a avaliação sugerir previamente uma composição suficientemente forte de viabilidade e conveniência. Nesse sentido, McMullen e Shepherd (2006) indicam que a redução da incerteza passa a ser fundamental para desencadear a ação empreendedora, dado que a mera exposição a oportunidades não estimula a ação, se a dúvida prevalecer como resposta. Para explicar como as convicções sobre futuros empreendimentos são formadas, é importante observar como os empreendedores controlam a incerteza, tornando-a no máximo uma percepção de risco. 
Para agir, os agentes precisam minimizar mentalmente os obstáculos e formar uma ideia de que as coisas não darão errado no curso da ação.

Autio et al. (2013) consideram que a redução da incerteza é impulsionada por dois fatores. Primeiro, a exposição de um indivíduo a mundos de pensamento alternativos, quando o empreendedor participa de diversas redes pelas quais transitam informações que podem ser combinadas com aquelas que ele domina. Segundo, sua participação, a atenção dada às declarações do indivíduo nessas redes. A intensidade da comunicação em redes tende a contribuir para a tomada de decisão, uma vez que o agente se municia de certezas sobre seu projeto, manipulando informações. Ambos são mecanismos sociais que enfatizam o papel da informação obtida através de interações sociais.

Tendo em vista que as tendências sociais costumam ser menos previsíveis do que as tendências tecnológicas, este papel de mecanismos sociais enfatiza o caráter intersubjetivo da redução da incerteza, em que crenças sobre a viabilidade comercial das oportunidades emergem por meio de interações sociais. Sobre isso, Kirzner (1997) já indicava que a distribuição de informação pelos sistemas sociais regula, de certa forma, a descoberta de oportunidades. Para o autor, os indivíduos acessam parcialmente, manipulam, criam em parte essas informações, através de suas interações. Por causa do modo como a informação é incorporada nos sistemas sociais, ela não é totalmente cognoscível ao agente individual, mas gradualmente revelada por meio de outros. A exposição a informações privilegiadas, junto a redes de interações densas, pode favorecer a decisão de empreender.

A análise dessa bibliografia sobre o comportamento empreendedor permite concluir que os processos associados com a descoberta, avaliação e exploração de oportunidades derivam da habilidade cognitiva dos agentes para adquirir, manipular e combinar informações e transformá- 
-las em um empreendimento. A convicção em uma oportunidade deixa em evidência que há um fator decisório preponderante dirigindo a ação empreendedora. $\mathrm{O}$ agente só decide explorar uma oportunidade reconhecida quando acredita que tem reais chances de obter um retorno maior do que o custo de sua busca, ou seja, quando constatar que uma oportunidade não só existe, como é atraente. Em síntese, levar a cabo a exploração de uma oportunidade é uma escolha, paradoxalmente, condicionada por brechas em um meio e calculada e imaginada pelos agentes. No caso do empreendedorismo intensivo em conhecimento, não parece analiticamente razoável minimizar a importância do perfil, trajetória, redes, habilidades e recursos mobilizados por pesquisadores e tecnólogos na condução do processo empreendedor em questão e atribuí-la exclusivamente às novas condições criadas por políticas institucionais. Essa interpretação parece no mínimo questionável se tratada como fator determinante, na medida em que esfacelaria o núcleo dinâmico e diferenciador dessa forma especial de ação empreendedora, tão dependente de cognoscibilidade baseada em informações técnicas, dados científicos e interações acumuladas.

\section{Algumas evidências sobre o movimento empreendedor no Brasil}

Existe certo consenso na literatura de que a regulamentação de novas políticas de Ciência, Tecnologia e Inovação foram um marco histórico para a institucionalização de habitats de inovação no Brasil (Morais, 2007; Viotti, 2008; Arbix, 2010; Balbachevsky, 2010). Estudo realizado pela Associação Nacional de Entidades Promotoras de Empreendimentos Inovadores (Anprotec), em parceria com o Ministério da Ciência, Tecnologia e Inovação (MCTI), mostra que, em 2011, existiam no Brasil 2.640 
empresas incubadas em 384 incubadoras, sendo que estas já haviam graduado 2.509 empreendimentos. As empresas graduadas faturavam R\$ 4,1 bilhões anuais, empregando 29.205 pessoas. As empresas incubadas, por sua vez, geravam 16.394 postos de trabalho, com faturamento anual de $\mathrm{R} \$ 533$ milhões (Anprotec, 2012).

Outro estudo realizado pelo Programa Nacional de Apoio às Incubadoras de Empresas e Parques Tecnológicos identificou e existência, em 2013, de 94 iniciativas de parques científicos e tecnológicos no Brasil, sendo que 28 destes estavam em plena operação. Nesses parques, residiam 939 empresas que geravam 29.909 empregos, absorvendo mão de obra altamente qualificada, a maior parte com nível superior completo $(80,4 \%)$, destacando-se também a participação de mestres e doutores (13,5\%). Os dados demonstram que a composição do mercado de trabalho das empresas sediadas em parques tecnológicos destoa significativamente do que se observa na realidade das empresas tradicionais ( $\mathrm{PNI}, 2013$ ).

Estudos que defendem os fatores ambientais como lastro do crescimento do empreendedorismo intensivo em conhecimento no Brasil costumam associar sua expansão aos avanços em políticas governamentais², promovidas desde o final dos anos 1990. Porém, deve-se registrar que, nesse mesmo contexto, o empreendedorismo já vinha se modificando no país, de modo geral. A redução do empreendedorismo por necessidade pode ser considerada um sinal animador, pois expressa uma reversão da tendência histórica da abertura de empresas como alternativa de renda para aqueles que não conseguem emprego.

Nesse sentido, segundo dados do Relatório Global Entrepreneurship Monitor (GEM, 2014), no Brasil, em 2014, 71\% do total da atividade em-

\footnotetext{
${ }^{2}$ Em 1998, o Governo Federal, para fomentar o surgimento de micro e pequenas empresas inovadoras, por meio do Ministério de Ciência e Tecnologia (MCT) e suas agências CNPq e FINEP; do Ministério do Desenvolvimento, Indústria e Comércio (MIDC); do Serviço Brasileiro de Apoio às micro e pequenas empresas (SEBRAE) e de outros parceiros, lança o Programa Nacional de Apoio às Incubadoras de Empresas (PNI).
} 
preendedora $^{3}$ foi de empresas abertas por uma questão de oportunidade em oposição ao empreendedorismo por necessidade, sendo que, em 2002 , a proporção era $42 \%$. No entanto, a maior parte das motivações dos novos empreendedores por oportunidade ainda não se diferencia significativamente daquelas dos que empreendem por necessidade. Alguns dados podem ser considerados alarmantes, pois indicam que os novos negócios continuam tendo pouca ou nenhuma inclinação para a inovação. Esse fato parece refletir uma característica do empresariado brasileiro, que ainda se apresenta de maneira conservadora diante da atividade econômica inovadora. Nesse sentido, mesmo nas ocorrências de empreendedorismo por oportunidade, há predominância em atividades pouco dinâmicas, como serviços de alimentação e bebida (10,3\%), tratamento de beleza $(7,0 \%)$, artigos de vestuário e acessórios ${ }^{4}$ : "No que tange ao empreendedorismo por oportunidade, notadamente são os restaurantes de bairro, os cabeleireiros e as lojas de roupa que capturam o imaginário dos brasileiros" (GEM, 2014, p. 81).

Ademais, entre os empreendedores iniciantes no país, 95,2\% revelam utilizar tecnologias que têm mais de cinco anos de uso; 78,1\% declararam não considerar novo o produto ou serviço oferecido; $60,4 \%$ consideram que há muito concorrentes no mercado; $92,6 \%$ afirmam não possuir clientes no exterior; somente $25,7 \%$ usam a internet para vender produtos e serviços. Mesmo entre os empreendedores estabelecidos (42 meses ou mais), a situação não é diferente: $84,2 \%$ não consideram seu produto ou serviço novo; $98,3 \%$ utilizam tecnologias com mais de cinco anos; $69,3 \%$ consideram que há muitos concorrentes; $92,9 \%$ não possuem clientes no exterior; $15,5 \%$ usam a internet para vendas.

\footnotetext{
${ }^{3}$ O Total da Atividade Empreendedora é medido pelo GEM como a percentagem da população entre 18 a 64 anos que ou está abrindo uma empresa ou é proprietária de um negócio. ${ }^{4}$ A categoria "outras atividades" é a com maior porcentagem, 43,7\% (GEM, 2014, p. 80).
} 
A partir desses dados, o relatório estima os níveis de qualificação dos empreendedores brasileiros, em termos de características ligadas à inovação $0^{5}: 57,7 \%$ não possuem qualquer característica inovadora, 34,5\% uma característica inovadora, 6,3\% duas e 1,5\% três ou mais: "Os novos empreendimentos são majoritariamente não inovadores e, portanto, com mais concorrentes e menor expectativa de criação de empregos e faturamento" (GEM, 2014, p. 102). Além disso, 86,6\% dos empreendedores iniciantes não procuram qualquer forma de apoio externo (de universidades, organizações, agências ou associações); 34\% não possuem ensino médio completo; 55,4\% têm até ensino superior incompleto; 10,6\% até mestrado completo; $58,9 \%$ dos iniciantes têm renda familiar de até três salários mínimos; $67 \%$ faturam até $\mathrm{R} \$ 24$ mil anuais; 84,1\% não possuem empregados e mais da metade $(55,9 \%)$ não pretendem gerar nenhum emprego nos próximos cinco anos.

Esses dados permitem afirmar que, no Brasil, o empreendedor tradicional continua privilegiando a imitação à inovação, assumindo ou desconhecendo o ônus dessa decisão. Ao escolher atuar em mercados saturados, concorre-se por preço, subestimando, por incapacidade ou ingenuidade, os benefícios da competição com base na diferenciação de bens e serviços. A consequência é uma concorrência espúria, que resulta na redução do lucro, inexistência de parcerias e aumento da mortalidade das empresas. Ao que tudo indica, ainda há problemas latentes na formulação das políticas de geração de emprego e renda, assim como nos tão propalados novos marcos legais de Ciência, Tecnologia e Inovação, pois ainda não se obtêm sequer resultados práticos razoáveis no que se refere à

\footnotetext{
${ }^{5}$ São seis as características consideradas inovadoras que qualificam o empreendimento: 1) conhecimento dos produtos ou serviços: novos para alguns ou para todos; 2) concorrência: poucos concorrentes ou nenhum; 3) orientação internacional: acima de 1\% dos consumidores são do exterior; 4) idade da tecnologia ou processo: até 5 anos; 5$)$ expectativa de geração de empregos: mais de 10 empregados e com a expectativa de aumentar em $50 \%$ nos próximos 5 anos; 6) faturamento: acima de 60 mil reais anualmente (GEM, 2014, p. 100-101).
} 
capacidade de estimular um movimento empreendedor mais qualificado no país. Mesmo que possam ser identificados casos diferenciados, entre os quais o tipo especial de empreendedorismo que estamos investigando, estes ainda são praticamente marginais. Nesse sentido, deve-se pressupor que o agente empreendedor típico do empreendedorismo tecnológico apresente qualidades diametralmente opostas às do empreendedor brasileiro médio. Daí a razão de dar continuidade a tais estudos, avançando sobre novas perspectivas de análise que visem a melhor compreender a origem e a evolução da ação empreendedora nesse segmento emergente.

Conhecimento, tecnologia e ação empreendedora: agenda de pesquisa

Para fundamentar uma problematização sobre como surge e se desenvolve o empreendedorismo tecnológico no Brasil, partimos da concepção de que potenciais empreendedores inseridos em meios científicos e tecnológicos podem produzir transformações culturais nos seus meios de atuação, respondendo subjetivamente a circunstâncias com que se deparam, perseguindo interesses, superando barreiras e fazendo escolhas, mesmo que dentro de limites determinados por valores e fatores institucionais, que podem tanto constranger como estimular cursos alternativos de ação.

A teoria do empreendedorismo assimila tal concepção da ação humana e indica que o processo da ação empreendedora é conduzido por competências e habilidades que os agentes econômicos adquirem para reconhecer oportunidades. Mas, e no caso do empreendedorismo intensivo em conhecimento, o que estaria neste horizonte? Em que medida pesquisadores e tecnólogos decidem criar empresas de base tecnológica como alternativa de carreira? Como eles julgam valer a pena perseguir oportunidades a partir de contextos pouco afeitos à inovação e nem sem- 
pre permeáveis ao uso comercial da ciência? Nesta seção, são levantados aspectos da perspectiva de interpretação mais subjetiva do fenômeno em questão, a partir de evidências observadas em entrevistas e questionários aplicados, nos últimos três anos, junto a empreendedores de 68 empresas de base tecnológica, de diferentes regiões do país. Cabe ressaltar que os casos foram escolhidos aleatoriamente, identificados pelo critério start-ups e spin-offs criadas entre 2010 e 2015, independentemente de seu ramo de atividade econômica.

Como indica a teoria da ação empreendedora, a racionalidade dos empreendedores (orientada por probabilidades - reais ou supostas, presentes ou futuras) está circunscrita ao estoque de informações que detêm e à capacidade cognitiva que possuem para acessar novas informações e processá-las na forma de empreendimentos. No caso do empreendedorismo tecnológico, a ação empreendedora desencadeada incorpora um fator qualitativo determinante, que diz respeito à aplicação de conhecimentos técnico-científicos acumulados e de práticas relacionais típicas, em geral trazidas do ambiente universitário. Esse é um bom ponto de partida para compreender o sentido do comportamento econômico de pesquisadores e de tecnólogos quando decidem empreender.

A ação econômica desempenhada por esses potenciais empreendedores implica necessariamente considerar a intensidade de conhecimento e a complexidade de interações a que estão expostos e que trazem de suas trajetórias profissionais. Cabe destacar, entretanto, que nem todos os pesquisadores e tecnólogos são simpáticos ao empreendedorismo e possuem a disposição para empreender. Centramos nosso diagnóstico no caso daqueles que efetivamente criaram empresas e que, por suposição, são adeptos da atividade empreendedora. Assim, se considerarmos que a qualidade da ação empreendedora pode ser moldada pelo estoque de conhecimentos mobilizado pelos agentes que empreendem e pela for- 
ma como podem combinar as informações a que têm acesso, é correto presumir que a potencialidade cognitiva de pesquisadores e tecnológos para tornarem-se empreendedores inovadores seria diferenciada. Não por acaso, a literatura especializada informa que o grau de exposição a informações tecnológicas ajuda a reconhecer, a avaliar e a explorar oportunidades.

Autio et al. (2013) explicam que, em contextos caracterizados por mudanças tecnológicas frequentes, os empresários potenciais estão imersos em dois tipos de domínios interligados de informação: um associado com os próprios avanços tecnológicos (meios) e outro derivado de necessidades sociais (fins). Esses domínios exerceriam forte influência sobre a decisão de explorar oportunidades, uma vez que a competência técnica e a categoria das interações aumentam o acesso à informação e favorecem a avaliação de oportunidades. Em praticamente todos os casos analisados em nossa pesquisa, o ato de criação das empresas de base tecnológica, está carregado de ideias, experiências e intenções obtidas em experiências compartilhadas com outros profissionais, em instituições de pesquisa e organizações científicas ou empresariais. Observou-se que tais relações são amadurecidas durante muito tempo, a partir da formação de sólidas redes profissionais e técnicas. Se, na gênese desses empreendimentos, pode haver carência de recursos tangíveis, na sua criação há profissionais entusiastas que dispõem de conhecimento original e/ou exclusivo e que nutrem tramas estratégicas de colaboração com outros profissionais, empresas e universidades.

Talvez, aqui esteja uma proposição-chave que diferencia o fenômeno analisado do movimento empreendedor mais geral que ocorre no país. No empreendedorismo intensivo em conhecimento, raramente são observados casos iniciados por necessidade, pois a maturação do negócio inovador exige dos empreendedores grande investimento de tempo 
e acúmulo de conhecimentos. Entre nossos 68 informantes, $77 \%$ consideram que o lucro deve ser consequência do seu trabalho; $68 \%$ revelam que o objetivo com o negócio é obter reconhecimento enquanto que para $18 \%$ a meta é ganhar dinheiro; apenas quatro afirmam ter iniciado o negócio por necessidade. Eles reconhecem que um empreendimento tecnológico envolve significativo risco e não produz ganhos econômicos imediatos. Por isso, o processo decisório raramente é individual, tendendo a ser uma iniciativa mais colaborativa. Não por acaso, $42 \%$ revelam ter sido procurados para participar do negócio e um único declarou ser centralizador e individualista. Dessa forma, a ação empreendedora que busca levar um artefato ou serviço tecnológico para o mercado acaba sendo motivada tanto pelo envolvimento pessoal com o projeto da empresa quanto por decisões compartilhadas: 97\% declaram ter paixão pelo empreendimento e $90 \%$ se consideram otimistas; para $77 \%$ a cooperação amplia as chances de sucesso e $75 \%$ preferem trabalhar em equipe.

Os depoimentos desses empreendedores de start-ups e spin-offs revelam como a ação empreendedora por eles desempenhada é especialmente rica em conexões cognitivas com outros, frequentemente, sócios potenciais, colegas, professores, parceiros e mentores. Portanto, o empreendedorismo tecnológico não se diferencia das iniciativas empresariais tradicionais apenas porque o processo empreendedor é conduzido por agentes que dominam conhecimentos científicos e tecnológicos. É interessante observar como eles também se encontram envolvidos com uma espécie de causa coletiva, interagindo em feiras, encontros, congressos e associações, e também estabelecendo interações mais espontâneas, no Facebook e no Linkedin, e em grupos de WhatsApp. Tivemos a oportunidade de ingressar como observadores em alguns desses canais e constatar como colaboram trocando informações, relatando suas experiências, fazendo sugestões aos demais, indicando canais de fomento e apontando 
investidores. Os relatos de experiências que circulam nesses espaços ampliam os estoques de informação e acabam sendo aprendizado decisivo para que tais agentes calculem os riscos inerentes à decisão de empreender. Nesse sentido, o aumento na ocorrência de experiências positivas influencia a decisão por seguir caminho já trilhado por precursores.

A teoria da ação empreendedora adequada à análise do empreendedorismo tecnológico permite sugerir ainda que a constituição dos quadros especulativos, que conduzem pesquisadores e tecnólogos a adotarem uma postura empreendedora, depende da sua participação em redes densas de colaboração profissional e do grau de atenção que recebem em canais de interlocução que cultivam entre si - e para onde tentam atrair a atenção da esfera econômica. Os pesquisadores e os tecnólogos que procuram empreender agem a partir dessas pontes forjadas entre o seu campo profissional originário e nichos especializados de mercado. Tais pontes permitem flertar com novas redes de relações tecnológicas, mas também com redes de natureza comercial; ao mesmo tempo, são canais que amenizam incertezas que pairam entre a decisão de criar um negócio e a de colocar-se em um emprego estável no seu campo profissional.

Nossa pesquisa sugere que os empreendimentos tecnológicos não são exclusivos dos habitats de inovação artificialmente concebidos. Essas empresas não começam apenas em incubadoras assim como sua existência não se restringe aos parques tecnológicos. Muitas experiências observadas extrapolam essa forma de tutela. Entre os 68 empreendimentos investigados, $75 \%$ indicaram estabelecer redes com universidades, sendo $62 \%$ na origem do negócio e $51 \%$ no seu desenvolvimento; $65 \%$ não recorreram a recursos públicos e $40 \%$ não foram incubados. Contudo, não se trata, aqui, de desconsiderar a influência das políticas governamentais, dado que no país o número de empresas dependentes de recursos governamentais é significativo, notadamente nas áreas em que o processo de 
desenvolvimento da inovação é de custo muito elevado. Por outro lado, convém destacar que, apesar dos incentivos, poucos buscam na prática essa alternativa. No caso de atividades econômicas em que pesquisa e inovação têm menor curso, como por exemplo, tecnologia da informação, os incentivos também são ressaltados como obstáculos existentes ao empreendedorismo no país: dificuldade de abrir uma empresa, morosidade, linguagem dos projetos, intermitência dos apoios, contrapartidas, custos trabalhistas.

Dessa forma, independentemente das formas de relação com instituições de pesquisa consolidadas e com o poder público, proliferam experiências espontâneas, como os espaços de coworking, voltados à realização de networking entre profissionais de diversas áreas, onde pequenas empresas, freelancers e autônomos se relacionam entre si, com fornecedores e clientes. Para os empreendedores do conhecimento, tais espaços permitem encontros que podem originar novos negócios. Nesses canais autônomos e independentes, criados entre a esfera técnica e a econômica, potenciais empreendedores aprendem a lidar com as regras do jogo de mercado, acumulando informações estratégicas e desenvolvendo novas habilidades que, combinadas ao seu métier científico-tecnológico, potencializam a visualização de um negócio como opção atraente de carreira. Parece correto presumir, portanto, que o empreendedorismo tecnológico se revela não apenas como uma ação econômica, mas como uma ação simbólica, que desafia valores arraigados, a partir de comportamentos alternativos.

As reflexões aqui apresentadas nos levam a reforçar a importância da elaboração de uma agenda de pesquisa sobre as condições em que profissionais altamente qualificados decidem criar empresas de base tecnológica e, assim, compreender as singularidades como o fenômeno empreendedorismo tecnológico vem se constituindo na realidade brasileira. 
O ponto mais geral é o estudo sobre a diferenciação entre o modo como se desenvolve o processo cognitivo implícito ao empreendedorismo em geral, como ocorre no Brasil, e o empreendedorismo intensivo em conhecimento, em particular. Como visto anteriormente, os dados do Relatório GEM revelam a predominância no país de um movimento empreendedor pouco criativo que, em certa medida, expressa e reproduz o perfil cognitivo da massa dos empresários brasileiros. Outro ponto consiste em mapear as diferentes redes de colaboração da qual participam esses empreendedores, analisando como se engajam nas mesmas e as mantêm. Cabe identificar a natureza e a origem dos recursos que mobilizam e a forma como eles os acionam. O estudo sobre a robustez e heterogeneidade dessas redes assume importância fundamental para desvendar a decisão de empreender no fenômeno em questão.

Sem desconsiderar as mudanças institucionais e os arranjos decisórios que parecem ter favorecido em parte a expansão de empreendimentos intensivos em conhecimento no Brasil, também cabe investigar como os elementos mais subjetivos constitutivos desse tipo de empreendedorismo estão demarcados pela própria evolução da trajetória profissional desses indivíduos, revelando suas aspirações presentes e futuras. O fato evidente é que, mesmo sendo importantes os incentivos institucionais, estes não são os únicos meios utilizados pelos pesquisadores e tecnólogos empenhados em converter capital técnico-científico em capital econômico. Já se sabe que esse tipo de empreendedorismo costuma ter origem em relações prévias, cultivadas no ambiente universitário e em experiências profissionais de natureza não acadêmica, junto a empresas e mercados de tecnologia. Estudos sobre o trânsito simultâneo dos pesquisadores-empreendedores entre ambientes acadêmicos (grupos de pesquisa, eventos científicos) e espaços comerciais (feiras tecnológicas, associações), bem como sobre a convergência de interesses envolvidos, podem favorecer 
a investigação sobre como os agentes compreendem e desafiam o seu campo de atuação profissional e revelar a percepção que os mesmos têm sobre seu papel em importantes mudanças institucionais, a partir da ação econômica que desempenham competentemente.

\section{Conclusão}

Mais do que reproduzir elementos já problematizados, até mesmo pela teoria econômica mainstream, acerca das limitações da racionalidade dos agentes econômicos, a proposta deste ensaio acabou por retomar, justamente, abordagens que enfatizam o processo de ação, sem deixar de remeter à importância de mecanismos institucionais, para a explicação dos fenômenos econômicos, porém não os tomando como fator determinante incondicional. Os próprios esforços teóricos da nova sociologia econômica detiveram-se, nas últimas décadas, em não fazer tábula rasa dos condicionantes estruturais e institucionais da ação econômica, se não que chamam atenção para a capacidade dos agentes em mobilizar tanto recursos quanto outros agentes em torno de formas alternativas de ação, em diferentes mercados de atuação. Nesse sentido, a problematização de como se dão as relações entre os agentes e entre eles e as instituições, sugerida no ensaio para compreender o fenômeno econômico do empreendedorismo intensivo em conhecimento, parte da "teoria da ação empreendedora" e avança, conectando-a à teoria sociológica existente, para melhor avaliar as contribuições da primeira ao aprimoramento de lacunas da segunda.

Autores como Granovetter (1973, 1985) e Fligstein (2007) elaboraram um cenário perene de interpretação dos fenômenos econômicos, apontando para perspectivas teóricas antagônicas sobre o papel dos atores nos processos sociais. Por um lado, as teorias neoinstitucionalistas, em 
sociologia, apresentam a concepção de que as instituições - compreendidas enquanto regras e significados compartilhados - condicionam as relações sociais, ajudam a definir quem ocupa qual posição nessas relações e orientam interações ao apresentar quadros de significados que ajudam os agentes a interpretar a dinâmica social. Contrariamente às ideias advogadas pelos neoinstitucionalistas, a teoria da escolha racional defende que as instituições são o resultado das interações de atores racionais e individuais em situações semelhantes a jogos de regras e recursos fixos.

Enquanto as teorias neoinstitucionalistas definem a formação de ordens sociais, enfatizando as disputas entre grupos dominantes e dominados dentro de campos, para estabelecer e definir padrões de institucionalizações materiais e simbólicos, a teoria da escolha racional sublinha que os agentes possuem interesses e se envolvem agressivamente em interações estratégicas, com a finalidade de viabilizá-los. Os autores da sociologia econômica evidenciam limitações interpretativas em ambas essas perspectivas, afirmando que os neoinstitucionalistas enfatizam o impacto das estruturas sociais na ação humana, reduzindo os indivíduos a agentes supersocializados, propagadores de significados compartilhados e seguidores de roteiros; por outro lado, os interesses individuais destacados pela teoria da escolha racional não podem ser simplesmente concebidos à parte de algum enraizamento social, a fim de evitar a construção teórica de um agente atomizado, subsocializado.

Visando superar esse impasse teórico, a nova sociologia econômica advoga que os agentes devem ser considerados como atores hábeis, que monitoram e interpretam o contexto e agem refletindo sobre a necessidade de mudanças nos campos onde atuam, empenhando-se em induzir a cooperação de outros para atingir certos fins (Fligstein, 2007; Fligstein; McAdam, 2012). Ademais, no fluxo da sua conduta, os indivíduos se engajam estrategicamente em redes de relações, através das quais trocam 
ideias, experiências e intenções, superando barreiras e criando pontes para erguer novos mundos sociais (Burt, 2004; Granovetter, 1973, 1985; Nee; Ingram, 2001; Ferrary; Granovetter, 2009).

A abordagem teórica dos campos de ação (Fligstein, 2007; Fligstein; McAdam, 2012) tem sido considerada instrumento pertinente para compreender a dinâmica da estabilidade e da mudança em espaços sociais. Trata-se de um aprofundamento da teoria de campos, consagrada por Bourdieu, em que, basicamente, dois grupos concorrentes disputam os recursos de um campo. Os incumbentes são os atores melhor posicionados, com maior quantidade de recursos, que definem os propósitos do campo e a forma como ele se organiza. Os desafiantes têm menor influência sobre a dinâmica do campo, precisando, em geral, submeter-se à lógica dominante para sobreviver. Desse modo, as instituições de um campo refletem configurações de poder, em que posições se definem, favorecendo os dominantes. Novas ordens se constroem, quando emergem "campos de ação estratégica", visando superar alguma crise interna ou externamente deflagrada, obrigando incumbentes e desafiantes a interagirem. Sob tais circunstâncias, os dominantes adotam postura conservadora, buscando preservar as fontes culturais e políticas de suas vantagens, buscando apoio nas estruturas de governança consagradas. Já os desafiantes buscam forjar coalizões alternativas e agem conforme uma visão compartilhada de como o campo pode vir a ser reorganizado.

Paralelamente, a abordagem teórica de redes sociais (Granovetter, 1973, 1985; Burt, 2004) tem sido considerada um instrumento decisivo para compreender o processo de formação e de desenvolvimento de alianças estratégicas, visto que, por meio das suas redes de relacionamentos sociais, os agentes tornam-se capacitados a melhor visualizar alternativas e explorá-las oportunamente. Granovetter $(1973,1985)$ expôs a forma como a ação econômica acaba sendo influenciada pela força dos 
laços interpessoais mantidos pelos agentes, e pelo modo como recursos, informações e ideias fluem e transitam nessas redes. Burt (2004) destaca que o elemento central a ser analisado para compreender a dinâmica social não é qualquer tipo de laço em particular, mas sim os buracos estruturais a serem atravessados, haja vista uma significativa correlação entre buracos estruturais e a geração de "boas ideias". Assim, os agentes próximos a buracos em uma estrutura social - os brokers - são mais propensos a identificarem melhores soluções e ou alternativas, pois podem, através do estabelecimento de pontes, conectar e intercambiar um conjunto de práticas e crenças existentes, mas até então isoladas: "o comportamento, a opinião e a informação são mais homogêneos dentro do que entre grupos. As pessoas se concentram em atividades de seus grupos, o que cria buracos de informações entre grupos, ou, mais simplesmente, buracos estruturais" (Burt, 2004, p. 353). Nesse sentido, a novidade surge quando grupos diferentes se chocam. Os agentes que possuem contatos diversificados e localizados em redes diversas estão mais propensos a estabelecer pontes entre buracos estruturais e aproveitar vantagens, que, de outra forma, seriam invisíveis.

Esse é o ponto de partida para trazer elementos para uma agenda de pesquisa sobre a ação empreendedora. A problematização aqui em voga, então, e que nos conduziu a complementar a perspectiva interpretativa sobre o que impulsiona efetivamente o empreendedorismo intensivo em conhecimento, mobiliza aspectos da teoria da ação empreendedora e destaca a importância desse fenômeno enquanto opção empírica para ilustrar novos desdobramentos da sociologia da ação econômica. Esse perfil especial de empreendedor merece maior atenção, pois, efetivamente, parece constituir o caso de agentes que se colocam mais próximos de buracos estruturais, identificando ações alternativas, fazendo escolhas ousadas e tomando a arriscada decisão de assumirem o papel de brokers. 
De que modo cientistas e pesquisadores se aproximaram desses buracos estruturais e por que escolheram ficar nas suas proximidades? Por que assumiram o alto custo dessa decisão e não optaram por um caminho mais cômodo? São eles sempre agentes desafiantes dentro de um campo? Sugere-se, pois, uma hipótese alternativa para a compreensão do fenômeno em tela, que não toma como questão-chave as políticas institucionais de estímulo a tal ação, mas o sentido elaborado por tais agentes quando exploram caminhos alternativos, as razões que os levam a assumir tais práticas e, até mesmo, em que medida aderem a políticas e programas de incentivo. No caso específico do país, ao se adotar uma linha interpretativa que enaltece as políticas como fator determinante para iniciativas de empreendedorismo tecnológico, incorre-se em tomar esses "buracos estruturais" como "feridas" e as próprias políticas de estímulo como "suturas" para curá-las. Mas, nenhuma cura efetivamente se dá pelo curativo aplicado, senão que pela reação própria do organismo.

A teoria da ação empreendedora carrega elementos importantes para se pensar a formação desses brokers, uma vez que a decisão de explorar uma oportunidade reflete a escolha de agentes, mais ou menos induzida por outros, por seguir um caminho entre alternativas possíveis. Nesse sentido, há uma contribuição decisiva para se compreender o que motiva e condiciona um agente a se envolver em interações estratégicas com outros, assumindo uma posição em um espaço social. Como sustenta a teoria da ação empreendedora, a decisão por um caminho dentre outros é um processo cognitivo baseado em informação acumulada, selecionada e analisada, por meio do qual são estimadas consequências para a ação, constituindo-se a ocasião em que o indivíduo se convence racional e emocionalmente de que algo é possível (Hastie, 2001; McMullen; Shepherd, 2006, Shepherd et al., 2007). 
A escolha por uma posição dentro de um campo emanaria de um processo cognitivo de redução de incertezas sobre um caminho a ser tomado. Essa é uma condição muito presente na ação dos empreendedores tecnológicos no país, já que nem sempre encontram respaldo em seu campo de atuação profissional e poucos possuem estímulos externos, dada sua presença em um ambiente empresarial restritamente afeito à inovação. Neste tipo de contexto, as crenças sobre a viabilidade das oportunidades acabam sendo alavancadas por meio de interações, quando esses indivíduos acessam parcialmente, manipulam, criam em parte novas informações, que não são totalmente cognoscíveis ao agente individual, mas gradualmente reveladas por meio de cooperação (Kirzner, 1997). Os brokers, então, seriam agentes mais expostos a pensamentos alternativos, por meio de sua participação e da atenção que recebem das diversas redes por onde transitam, acumulando informações novas que podem ser combinadas com as que já dominam (Autio et al., 2013).

Tratou-se, aqui, de levantar hipóteses gerais para uma interpretação alternativa acerca do empreendedorismo no Brasil, considerando pensá-lo empiricamente a partir de uma concepção ligada aos desafios e condições que se colocam aos empreendedores nas atividades que envolvem conhecimento científico e tecnológico. De modo geral, os resultados da pesquisa exploratória em andamento ressaltam a importância de dar maior destaque às circunstâncias subjetivas que envolvem a criação de pequenas e médias empresas de base tecnológica no país, aparentemente visto que o seu surgimento não apenas ocorre em paralelo como também opera subjacentemente às mudanças institucionais e aos novos arranjos legais voltados à relação universidade-empresa e à inovação. Na prática, esses novos dispositivos - mesmo que deem margem para que a ação empreendedora se desenvolva a partir do campo científico-tecnológico sem maiores entraves - não são suficientes para estimular o empreende- 
dorismo tecnológico como um movimento espontâneo e sustentável, ou seja, mais promovido pela agência dos atores econômicos e menos dependente da tutela de instituições de pesquisa e de agências de fomento que atuam em lógicas próprias e ainda muito arraigadas.

De fato, dados preliminares de pesquisa indicam que os empreendedores do conhecimento estão lutando consigo mesmos, contra uma cultura profissional incorporada e contra um ambiente de negócios pouco atrativo e afeito ao risco. Nossa proposta foi fornecer algumas pistas para maturar o estudo dessa forma especial de ação empreendedora, que não é apenas importante para acompanhar o fenômeno em si, mas por poder prescrever um quadro mais abrangente para monitorar as tendências do próprio movimento empreendedor no país. Todavia, uma proposição mais definitiva sobre o tema deve aguardar um momento em que resultados empíricos mais densos possam corroborá-la.

Daniel Gustavo Mocelin é sociólogo e Professor Adjunto do Departamento de Sociologia do Instituto de Filosofia e Ciências Humanas da UFRGS.

\daniel.mocelin@ufrgs.br

Lucas Rodrigues Azambuja é Professor Adjunto I no IBMEC-MG e Coordenador do Grupo de Estudos Laboratório de Análise de Ambiente de Negócios.

\azambuja81@gmail.com 


\section{Referências}

1. ALDRICH, H. Using an ecological approach to study organizational founding rates. Entrepreneurship Theory Pract, v. 14, n. 3, p. 7-24, 1990.

2. ALVAREZ, S. A.; BARNEY, Jay B. Discovery and creation: Alternative theories of entrepreneurial action. Strategic Entrepreneurship Journal, v. 1, p. 11-26, 2007.

3. ANPROTEC - Associação Nacional de Entidades Promotoras de Empreendimentos Inovadores. Estudo, Análise e Proposições sobre as Incubadoras de Empresas no Brasil. Ministério da Ciência, Tecnologia e Inovação. Brasília: ANPROTEC, 2012.

4. ARANHA, J. A. S. Incubadoras. IN: PAROLIN, S. R. H.; VOLPATO, M. (Orgs.). Faces do empreendedorismo inovador. Curitiba: SENAI/SESI/IEL, 2008.

5. ARAÚJO, M. H. et al. Spin-off acadêmico: criando riquezas a partir de conhecimento e pesquisa. Química Nova, São Paulo, v. 28, suplemento, p. 26-35, nov./ dez. 2005.

6. ARBIX, G. Caminhos Cruzados: Rumo a uma estratégica de desenvolvimento baseada na inovação. Novos Estudos, CEBRAP, n. 87, p. 13-33, 2010.

7. ARBIX, G.; CONSONI, F. Inovar para transformar a universidade brasileira. Revista Brasileira de Ciências Sociais, São Paulo, v. 26, n. 77, p. 205-24, 2011.

8. AUTIO, E.; DAHLANDER, L.; FREDERIKSEN, L. Information exposure, opportunity evaluation, and entrepreneurial action: an investigation of an online user community. Academy of Management Journal, v. 56, n. 5, p. 1348-71, 2013.

9. BALBACHEVSKY, E. Entraves e incentivos para o desenvolvimento de sinergias entre universidade e sociedade na produção do conhecimento: a experiência da América Latina. Anais... 34 Encontro Anual da ANPOCS, Caxambú-MG, 2010.

10. BARCELOS, R. L. G.; MOCELIN, D. G. Ciência e mercado: Impasses na institucionalização de práticas empreendedoras em uma universidade pública brasileira. Rev. bras. Ci. Soc., São Paulo, v. 31, n. 92, p. 1-25, 2016.

11. BURT, R. S. Structural Holes and Good Ideas. American Journal of Sociology, v. 110, n. 2, p. 349-99, 2004.

12. CARNOY, M.; CASTELLS, M.; BENNER, C. Labour Markets and Employment Practices in the Age of Flexibility: A Case Study of Silicon Valley. International Labour Review, v. 136, n. 1, p. 27-48, 1997.

13. CHOI, Y. R.; SHEPHERD, D. A. Entrepreneurs decisions to exploit opportunities. Journal of Management, v. 30, p. 377-95, 2004. 
14. COLYVAS, J. A.; POWELL, W. W. From Vulnerable to Venerated: the Institutionalization of Academic Entrepreneurship in the Life Science. Research in the Sociology of Organization, v. 25, p. 219-59, 2007.

15. COLYVAS, J. A.; POWELL. W. W. Roads to Institutionalization: The Remaking of Boundaries between Public and Private Science. Research in Organizational Behavior, v. 27, p. 305-53. 2006.

16. CÔRTES, M. R. et al. Cooperação em Empresas de Base Tecnológica. São Paulo em Perspectiva, v. 19, n. 1, jan./mar. 2005, p. 85-94.

17. COZZI, A.; JUDICE, V.; DOLABELA, F.; FILION, L. J. (Orgs.). Empreendedorismo de base tecnológica: spin-off: criação de novos negócios a partir de empresas constituídas, universidades e centros de pesquisa. Rio de Janeiro: Campus, 2008.

18. DAGNINO, R.; DIAS, R. A Política de C\&T brasileira: três alternativas de explicação e orientação. Revista Brasileira de Inovação, v. 6, p. 373-403, 2008.

19. DOSI, G. Technological paradigms and technological trajectories: a suggested interpretation of the determinants and directions of technical change. Research Policy, 1982.

20. DRUCKER, P. F. Innovation and entrepreneurship: practice and principles. London: Pan Books, 1986.

21. DAVENPORT, T. H. Thinking for a Living: How to Get Better Performance and Results from Knowledge Workers. Boston: Harvard Business School Press, 2005.

22. ECKHARDT, J. T.; SHANE, S. A. Opportunities and entrepreneurship. Journal of Management, v. 29, p. 333-49, 2003.

23. ELIASSON, G. From Employment to Entrepreneurship: Shifting Perspectives in Europe and the US on Knowledge Creation and Labour Market Competition. Journal of Industrial Relations, London, Sage, v. 48, n. 5, p. 633-56, 2006.

24. ETZKOWITZ, H. Hélice Tríplice. Universidade - indústria - governo: inovação em movimento. Porto Alegre: EDIPUCRS, 2009.

25. ETZKOWITZ, H.; LEYDESDORFF, L. The dynamics of innovation: From National Systems and "Mode 2" to Triple Helix of university-industry-government relations. Research Policy, n. 29, p. 109-23, 2000

26. FAIA, V. S.; ROSA, M. A. G.; MACHADO, H. P. V. Alerta Empreendedor e as abordagens causation e effectuation sobre empreendedorismo. Rev. adm. Contemp., v. 18, n. 2, p. 196-216, 2014. 
27. FERRARY, M.; GRANOVETTER, M. The Role of Venture Capital Firms in Silicon Valley's Complex Innovation Network. Economy and Society, v. 38, n. 2, p. 326-59, maio 2009.

28. FLIGSTEIN, N. Habilidade social e a teoria dos campos. Revista de Administração de Empresas, v. 47, n. 2, p. 61-80, 2007.

29. FLIGSTEIN, N.; McADAM, D. A theory of fields. New York: Oxford University, 2012.

30. FOSS, K.; FOSS, N. J. Understanding opportunity discovery and sustainable advantage: The role of transaction costs and property rights. Strategic Entrepreneurship Journal, v. 2, p. 191-207, 2008.

31. GAGLIO, C. M. The role of mental simulations and counterfactual thinking in the opportunity identification process. Entrepreneurship: Theory \& Practice, v. 28 , p. 533-52, 2004.

32. GAGLIO, C. M.; KATZ, J. A. The psychological basis of opportunity identification: Entrepreneurial alertness. Small Business Economics, v. 16, n. 2, p. 95-111, 2001.

33. GARTNER, W. B. A conceptual framework for describing the phenomenon of new venture creation. The Academy of Management Review, v. 10, n. 4, 696$706,1985$.

34. GIANTURCO, A. O Empreendedorismo de Israel Kirzner. São Paulo: Instituto Ludwig von Mises Brasil, 2014.

35. GLOBAL ENTREPRENEURSHIP MONITOR. Empreendedorismo no Brasil: 2014. Coordenação de Simara Maria de Souza Silveira Greco; autores: Tales Andreassi et al. Curitiba: IBQP, 2014. 212 p.

36. GRANOVETTER, M. The economic sociology of firms and entrepreneurs. IN: SWEDBERG, Richard (Org.). Entrepreneurship: The social science view. Oxford Management Readers, 2000. p. 244-75.

37. GRANOVETTER, M. Economic action and social structure: the problem of embeddedness. American Journal of Sociology, v. 91, n. 3, p. 481-510, 1985.

38. GRANOVETTER, M. The strength of weak ties. American Journal of Sociology, v. 78, n. 6, p. 1360-80, 1973.

39. GUIMARÃES, S. M. K. International Entrepreneurship in an emergent economy. In: BURGER-HELMCHEN, Thierry (Org.). Entrepreneurship: Gender, Geographies and social context. Rijeka: Intech, Open Access Publisher, 2012. p. 235-48. 
40. GUIMARÃES, S. M. K. Empreendedorismo intensivo em conhecimento no Brasil. Cad. CRH. v. 24, n.63, p. 575-92, 2011.

41. GUIMARÃES, S. M. K.; AZAMBUJA, L. R. Empreendedorismo high tech no Brasil: condicionantes econômicos, políticos e culturais. Sociedade e Estado, UnB, v. 25, p. 93-121, 2010.

42. HAYNIE, J. M.; SHEPHERD, D. A.; MCMULLEN, J. S. An opportunity for me? The role of resources in opportunity evaluation decisions. Journal of Management Studies, v. 46, p. 337-61, 2009.

43. HASTIE, R. Problems for judgment and decision making. Annual Review of Psychology, v. 52, p. 653-83, 2001.

44. HIRSCHMAN, A. O. The strategy of economic development. Connecticut: Yale University Press, 1958.

45. HOLCOMBE, R. G. The Origins of Entrepreneurial Opportunities. The Review of Austrian Economics, v. 16, n. 1, p. 25-43, 2003.

46. IORIO, U. J. Ação, Tempo e Conhecimento: A Escola Austríaca de Economia. São Paulo: Instituto Ludwig von Mises, 2011.

47. JACK, S. L.; ANDERSON, A. R. The effects of embeddedness on the entrepreneurial process. Journal of Business Venturing, v. 17, p. 467-87, 2002.

48. KIRZNER, I. Competição e atividade empresarial. São Paulo: Instituto Ludwig von Mises Brasil, 2012.

49. KIRZNER, I. Entrepreneurial discovery and the competitive market process: An Austrian approach. Journal of Economic Literature, v. 35, p. 60-85, 1997.

50. LA ROVERE, R. L. As Pequenas e Médias Empresas na Economia do Conhecimento: Implicações para Políticas de Inovação. IN: LASTRES, Helena; ALBAGLI, Sarita (Orgs.). Informação e globalização na era do conhecimento. Rio de Janeiro: Campus, 1999.

51. LAHORGUE, M. A. Polos, parques e incubadoras: Instrumentos de desenvolvimento do século XX. Brasília: ANPROTEC, 2005.

52. LEMOS, P. A. B. Inovação e empreendedorismo científico e tecnológico: alguns aspectos da experiência da Inova e da Unicamp. IN: SANTOS, M. E. R. dos; TOLEDO, P. T. M. de; LOTUFO, R. de A. (Orgs.). Transferência de Tecnologia: estratégias para a estruturação e gestão de Núcleos de Inovação Tecnológica. Campinas, SP: Komedi, 2009.

53. LUMPKIN, G. T.; DESS, G. G. Clarifying the entrepreneurial orientation construct and linking it to performance. Academy of Management Review, v. 21, n. 1, p. 135-72, 1996. 
54. MARTINELLI, Alberto. O contexto do empreendedorismo. IN: MARTES, Ana Cristina Braga (Org.). Redes e Sociologia Econômica. São Carlos-SP: Edufscar, 2009. (p. 207-237)

55. McCLELLAND, D. C. The achieving society. Princeton, New Jersey: D. Van Nostrand Company, 1961.

56. McMULLEN, J. S.; SHEPHERD, D. A. Entrepreneurial action and the role of uncertainty in the theory of the entrepreneur. Academy of Management Review, v. 31, p. 132-52, 2006.

57. MINTZBERG, H. Structure in Fives: Designing Effective Organizations. Englewood Cliffs, New Jersey: Prentice-Hall, 1983.

58. MORAIS, J. M de. Políticas de apoio financeiro à inovação tecnológica: Avaliação dos Programas MCT/FINEP para empresas de pequeno porte. IPEA, Texto de discussão $\mathrm{n}^{\circ}$ 1296. Brasília. 2007.

59. NEE, V.; INGRAM, P. Embeddedness and Beyond: Institutions, Exchange, and Social Structure. IN: BRINTON, M. C.; NEE, V. (Orgs.). The New Institutionalism in Sociology. Stanford: Stanford University Press, 2001. p. 19-45.

60. NEFF, G.; WISSINGER, E.; ZUKIN, S. Entrepreneurial Labor Among Cultural Producers: 'Cool' Jobs in 'Hot' Industries. Social Semiotics, v. 15, n. 3, p. 307-34, 2005.

61. NELSON, R. R..; WINTER, S. G. An Evolutionary Theory of Economic Change. Cambridge: Harvard University Press, 1982.

62. OWEN-SMITH, J.; POWELL, W. W. Careers and Contradictions: Faculty Responses on the Transformations of Knowledge and Its Uses in the Life Sciences. Research in the Sociology of Work, n. 10, p. 109-40, 2001.

63. PENROSE, E. The theory of the growth of the firm. Oxford: Basil Blackwell, 1959.

64. PNI - Programa Nacional de Apoio às Incubadoras de Empresas e Parques Tecnológicos. Estudo de Projetos de Alta Complexidade: indicadores de parques tecnológicos / Centro de Apoio ao Desenvolvimento Tecnológico. Ministério da Ciência, Tecnologia e Inovação - Brasilia: CDT/UnB, 2013.

65. ROSSITER, R. Networks, collaboration and the internationalisation of small and medium-sized enterprises: an interdisciplinary perspective on the network approach. Working Paper, Brandford, v. 3, n. 33, out. 2003.

66. RUZZIER, M.; HISRICH, R. D.; ANTONCIC, B. SME internationalization research: past, present and future. Journal of Small Business and Enterprise Development, v. 13, n. 4, p. 476-97, 2006. 
67. SAXENIAN, A. L. Venture capital in the "periphery": the new Argonauts, global search and local institution building. Economic Geography, v. 84, n. 4, p. 379-94, 2008.

68. SAXENIAN, A. L. Regional advantage: culture and competition in Silicon Valley and Route 128. Cambridge: Harvard University Press, 1994.

69. SCHUMPETER, J. A. "O Fenômeno Fundamental do Desenvolvimento Econômico". IN: A Teoria do Desenvolvimento Econômico [1934]. Coleção Os Economistas. Rio de Janeiro: Nova Cultural, 1985.

70. SHANE, S. Prior knowledge and the discovery of entrepreneurial opportunities. Organization Science, v. 11, p. 448-69, 2000.

71. SHANE, S.; VENKATARAMAN, S. The promise of entrepreneurship as a field of research. Academy of Management Review, v. 25, p. 217-226, 2000.

72. SHEPHERD, D. A.; MCMULLEN, J. S.; JENNINGS, P. D. The formation of opportunity beliefs: Overcoming ignorance and reducing doubt. Strategic Entrepreneurship Journal, v. 1, p. 75-95, 2007.

73. SHINN, T.; LAMY, H. Caminhos do conhecimento comercial: formas e conseqüências da sinergia universidade-empresa nas incubadoras tecnológicas. Scientia e Studia, São Paulo, v. 4, n. 3, 2006.

74. SILVESTRE, R. G. M. et al. Empreendedorismo inovador: perfil atual do empreendedorismo brasileiro segundo o Global Entrepreneurship Monitor. IN: PAROLIN, S. R. H.; VOLPATO, M. (Orgs.). Faces do empreendedorismo inovador. Curitiba: SENAI/SESI/IEL, 2008.

75. SOBRAL, F. A. da F. Novos Horizontes para a Produção Científica e Tecnológica. Caderno CRH (UFBA), v. 24, p. 519-34, 2011.

76. STOKES, D. E. O quadrante de Pasteur: a ciência básica e a inovação tecnológica. Campinas-SP: Editora da Unicamp, 2005.

77. SWEDBERG, R. The social science view of entrepreneurship: introduction and practical applications. IN: SWEDBERG, R. (Org.). Entrepreneurship: The social science view. Oxford Management Readers, 2000, p. 7-44.

78. THORNTON, P. H. The sociology of entrepreneurship. Annual Review of Sociology, n. 25, p. 19-46, 1999.

79. THORNTON, P. H.; RIBEIRO-SORIANO, D.; URBANO, D. Socio-cultural factors and entrepreneurial activity: An overview. International Small Business Journal, v. 29, n. 2, p. 105-18, 2011.

80. TIMMONS, J. A.; SPINELLI, S. New Venture Creation: Entrepreneurship for the 21st Century. Boston: Irwin McGraw-Hill, 2003. 
81. TREMBLAY, D.-G. Serviços intensivos em conhecimento e desenvolvimento de conhecimento coletivo no setor de multimídia em Montreal. IN: GUIMARÃES, S. M. K. (Org.) Trabalho, emprego e condições laborais em setores intensivos em conhecimento: Brasil, México e Canadá. Porto Alegre: Editora da UFRGS, 2009.

82. VIOTTI, E. B. Brasil: De política de C\&T para política de inovação? Evolução e desafios das políticas brasileiras de ciência, tecnologia e inovação. In: SEMINẢRIO INTERNACIONAL. Avaliação de políticas de ciência, tecnologia e inovação. Brasília: Centro de Gestão e Estudos Estratégicos (CGEE), 2008, p. 137-73.

83. WEBER, Max. A ética protestante e o espírito do capitalismo. São Paulo: Companhia das Letras, 2004. 355 p.

84. WHITTAKER, H. D. Comparative Entrepreneurship: the UK, Japan and the shadow of Silicon Valley. Oxford: Oxford University Press, 2009.

Recebido: 05.05.2017

Aceite final: 11.10.2017 